Quim. Nova, Vol. 35, No. 7, 1412-1416, 2012

\title{
COMPARAÇÃO DO PERFIL QUÍMICO ENTRE CACHAÇAS DE UM MESMO VINHO DESTILADAS EM ALAMBIQUES E EM COLUNAS
}

\author{
Felipe Augusto Thobias Serafim, Alexandre Ataíde da Silva, Carlos Alexandre Galinaro e Douglas Wagner Franco* \\ Instituto de Química de São Carlos, Universidade de São Paulo, CP 780, 13560-970 São Carlos - SP, Brasil
}

Recebido em 19/12/11; aceito em 6/3/12; publicado na web em 25/6/12

\begin{abstract}
CHEMICAL PROFILE COMPARISON OF SUGARCANE SPIRITS FROM THE SAME WINE DISTILLED IN ALEMBICS AND COLUMNS. Six wines were distilled in two different distillation apparatus (alembic and column) producing 24 distillates (6 for each alembic fraction - head, heart and tail; 6 column distillates). The chemical composition of distillates from the same wine was determined using chromatographic techniques. Analytical data were subjected to Principal Component Analysis (PCA) and Hierarchical Cluster Analysis (HCA) allowing discrimination of four clusters according to chemical profiles. Both distillation processes influenced the sugarcane spirits chemical quality since two types of distillates with different quantitative chemical profiles were produced after the elimination of fermentation step influence.
\end{abstract}

Keywords: sugarcane spirit, alembic; column.

\section{INTRODUÇÃO}

Uma das etapas mais importantes da produção de cachaça é o processo de destilação, o qual pode ser conduzido utilizando tanto alambiques de cobre (cachaça artesanal) como colunas de aço inoxidável (cachaça industrial). ${ }^{1-4}$

A produção de cachaça em larga escala se caracteriza pela utilização de colunas de aço inox, nas quais o processo de destilação é contínuo. A entrada do vinho dentro da coluna e as respectivas saídas do destilado e do vinhoto ocorrem simultaneamente, mas por diferentes vias. Na produção em pequena escala, o processo de destilação é realizado em alambiques de cobre, onde ocorre a separação do destilado em três diferentes frações através do processo denominado "corte". A primeira fração a ser recolhida é chamada de "cabeça", cuja separação remove o excesso de compostos mais voláteis e/ou mais solúveis em etanol do que em água. A segunda fração é o "coração", parte nobre do destilado, a qual é utilizada para fins comerciais. A última fração, a "cauda", contém o excesso de compostos menos voláteis que o etanol e mais solúveis em água do que em etanol, como o ácido acético e o 5-HMF. ${ }^{5,6}$ As frações cabeça e cauda são geralmente descartadas ou utilizadas por alguns produtores em uma próxima destilação, adicionadas a um novo vinho. Do 1,7 bilhão de litros de cachaça produzidos anualmente no Brasil, cerca de $30 \%$ são destiladas em alambiques. ${ }^{7,8}$

De acordo com o Conselho Estadual de Política Agrícola do Estado de Minas Gerais, a legislação brasileira não diferencia as cachaças em função dos processos de destilação, mas aplica taxas diferenciadas a estas. ${ }^{8} \mathrm{O}$ volume de produção e, portanto, o custo por litro do destilado torna a competição pelo mercado de aguardente de cana desfavorável aos produtores de cachaças de alambique. Este fato motiva estes últimos a pleitearem a rotulação das cachaças de acordo com o processo pela qual elas foram destiladas. Assim procedendo, entendem agregar valor a seu produto.

Ambos os destilados podem ser discriminados com base nas diferenças entre as suas respectivas composições químicas. ${ }^{9-11}$ Portanto, justificaria a inclusão da informação da procedência no rótulo das aguardentes. Entretanto, todas as amostras analisadas anteriormente

*e-mail: douglas@iqsc.usp.br retratam as diferenças entre os destilados de alambique e os de coluna, utilizando amostras provenientes da destilação de vinhos diferentes. Assim, as diferenças de perfis químicos entre as mesmas poderiam ser atribuídas aos diferentes procedimentos da etapa fermentativa, aos quais os caldos de cana foram submetidos e não somente ao processo de destilação.

Com o intuito de obter maiores informações sobre este assunto, foi avaliada a composição química das três frações de destilados obtidos durante a destilação em alambiques de cobre, comparando-as com a dos destilados de colunas de aço inox, oriundos do mesmo vinho.

\section{PARTE EXPERIMENTAL}

\section{Os sistemas de destilação}

Todos os sistemas de destilação, alambiques de cobre e colunas de aço inox, foram adquiridos de produtores brasileiros e manuseados pelos profissionais das respectivas destilarias, seguindo suas respectivas especificações técnicas. O processo de destilação em alambiques foi realizado em alambiques de um só corpo, com geometrias similares e capacidades variando de 180 a 400 L. Usou-se fogo direto no aquecimento dos alambiques. Para as colunas de aço inox, foi utilizado fluxo de vapor, o qual foi injetado na parte inferior das seções de esgotamento. As variações de temperatura dentro dos alambiques e na parte inferior das colunas foram de 75-90 e 104-106 ${ }^{\circ} \mathrm{C}$, respectivamente. $\mathrm{O}$ processo de cortes das frações de cabeça, coração e cauda foi realizado de acordo com a graduação alcoólica dos destilados, conforme será indicado mais a frente.

\section{Amostras}

A produção de aguardentes utilizando ambos os sistemas de destilação pelo mesmo produtor não é economicamente viável. Portanto, não é corriqueiro o acesso a amostras de um mesmo vinho destiladas em colunas de aço inox e em alambiques de cobre. Seis diferentes vinhos, oriundos de produtores diferentes, foram independentemente submetidos aos dois sistemas de destilação, gerando 24 amostras de destilados. Nenhum destes destilados foi submetido ao processo de envelhecimento e todos foram estocados em garrafas de vidro sob 
refrigeração $\left(4 \pm 1{ }^{\circ} \mathrm{C}\right)$ e analisados no período de 3 a 4 meses após sua coleta.

\section{Reagentes}

Todos os reagentes e os solventes utilizados foram de grau analítico (Fluka, Sigma-Aldrich, St. Louis, MO, USA; Mallinckrodt Baker, Xalostoc, Tlaxcala, México) e de grau HPLC (Merck, Mallinckrdt), respectivamente. Nas diluições e no preparo das soluções, foi utilizada água deionizada, obtida em sistema Milli-Q (Millipore, Bedford, MA, USA).

\section{Metodologia analítica}

Alcoóis superiores e ácido acético ${ }^{12}$

Metanol, propanol, isobutanol, 1-butanol, 2-butanol, álcool isoamílico e acido acético foram determinados por injeção direta de $1,0 \mu \mathrm{L}$ da amostra, sem pré-tratamento, em cromatógrafo para fase gasosa (Hewlett-Packard, HP 5890-A GC) acoplado a detector de ionização de chama (FID - Flame Ionization Detector) e utilizando uma coluna HP-FFAP (polietileno glicol esterificado; $50 \mathrm{~m} \mathrm{x} 0.20$ $\mathrm{mm} \times 0.33 \mu \mathrm{m}$ ). A temperatura do injetor e do detector foi de $250{ }^{\circ} \mathrm{C}$ e a razão de split foi de 1:20. A rampa de temperatura utilizada foi $55{ }^{\circ} \mathrm{C}(5 \mathrm{~min}) ;{ }^{\circ} \mathrm{C} \mathrm{min}{ }^{-1}$ até $100{ }^{\circ} \mathrm{C}(3 \mathrm{~min}), 5^{\circ} \mathrm{C} \mathrm{min}{ }^{-1}$ até $190{ }^{\circ} \mathrm{C}$ (30 min); $5{ }^{\circ} \mathrm{C} \min ^{-1}$ até $220{ }^{\circ} \mathrm{C}$ (15 min). A identificação e a quantificação dos compostos foram realizadas através da comparação do tempo de retenção dos padrões analíticos e pelo método de adição de padrão, respectivamente.

\section{Aldeídos e cetonas ${ }^{13}$}

Acetilcetona, formaldeído, 5-hidroximetilfurfural (5-HMF), acetaldeído, acroleína, furfuraldeído, propionaldeído, butiraldeído, benzaldeído, isovaleraldeído, valeraldeído e 2,3-butanodiona (diacetil) foram analisadas na forma de suas respectivas 2,4-dinitrofenil-hidrazonas (aldeídos-DNPHs) utilizando cromatógrafo HPLC Shimadzu, modelo LC-10AD, equipado com detector UV-vis diode array (Shimadzu SPD M6A, comprimento de onda = $365 \mathrm{~nm}$ ). A separação das hidrazonas foi realizada em coluna Shimadzu ShimPak C18 (25 cm x 4,6 mm i.d. x 5,0 $\mu \mathrm{m}$ ). O volume injetado foi de $20,0 \mu \mathrm{L}$ e o gradiente de eluição utilizado foi metanol/acetonitrila $(80 / 20)$ e água à razão de 60:40 (v/v) em modo isocrático por 9 $\min (1,00 \mathrm{~mL} / \mathrm{min})$, de 60:40 para 95:5 em $16 \mathrm{~min}(1,1 \mathrm{~mL} / \mathrm{min})$, de 95:5 para 60:40 em $9 \mathrm{~min}(1,0 \mathrm{~mL} / \mathrm{min})$, voltando ao modo isocrático 60:40 nos $15 \mathrm{~min}$ finais $(1,00 \mathrm{~mL} / \mathrm{min})$. A identificação e a quantificação dos compostos foram realizadas através da comparação do tempo de retenção dos padrões analíticos e pela curva de calibração, respectivamente.

\section{Carbamato de etila ${ }^{14}$}

A determinação da concentração de carbamato de etila foi realizada através da injeção direta de $1 \mu \mathrm{L}$ de amostra em modo splitless, sem pré-tratamento em cromatógrafo para fase gasosa, modelo GC17A (Shimadzu, Tokyo, Japan) acoplado a um espectrômetro de massa seletivo, modelo QP 5050A (Shimadzu, Tokyo, Japan) utilizando impacto eletrônico $(70 \mathrm{eV})$ como forma de ionização. O espectrômetro de massa foi operado no modo SIM $(\mathrm{m} / \mathrm{z} 62)$ e o carbamato de propila $(150 \mu \mathrm{g} / \mathrm{L})$ foi utilizado como padrão interno. Uma coluna HP-FFAP (polietileno glicol esterificado; $50 \mathrm{~m}$ x 0,20 $\mathrm{mm}$ x 0,33 $\mu \mathrm{m}$ ) foi utilizada. As temperaturas do injetor e da interface do detector foram 250 e $230{ }^{\circ} \mathrm{C}$, respectivamente. A rampa de temperatura utilizada foi de: $90{ }^{\circ} \mathrm{C}(2 \mathrm{~min})$; subindo à razão de $10^{\circ} \mathrm{C} \min ^{-1}$ até $150{ }^{\circ} \mathrm{C}(0 \mathrm{~min})$; $40{ }^{\circ} \mathrm{C}$ min $^{-1}$ até $230{ }^{\circ} \mathrm{C}$ (10 min). A quantificação do carbamato de etila foi realizada pelo método de adição de padrão.
Ésteres $^{15}$

Acetato de etila, butirato de etila, hexanoato de etila, lactato de etila, octanoato de etila, nanoato de etila, decanoato de etila, laurato de etila e octanoato de isoamila foram analisados pela injeção direta de $1 \mu \mathrm{L}$ de amostra em modo split (1:15) sem pré-tratamento, em cromatógrafo para fase gasosa, modelo GC17A (Shimadzu, Tokyo, Japan) acoplado a um espectrômetro de massa seletivo, modelo QP 5050A (Shimadzu, Tokyo, Japan) utilizando impacto eletrônico (70 $\mathrm{eV}$ ) como forma de ionização. Como padrão interno foi utilizado 4-methyl-2-pentanol. A separação dos ésteres foi realizada através de uma coluna capilar HP-FFAP, cujas características foram acima mencionadas. Ambas as temperaturas do injetor e da interface do detector foram de $220^{\circ} \mathrm{C}$. A programação da temperatura do forno foi de 35 a $180{ }^{\circ} \mathrm{C}$ em uma razão de $5{ }^{\circ} \mathrm{C} \mathrm{min}^{-1}$; de 180 a $220{ }^{\circ} \mathrm{C}$ a uma razão de $20^{\circ} \mathrm{C}$ min $^{-1}$ (5 min). A quantificação foi feita com base na curva de calibração.

\section{Ácidos orgânicos ${ }^{16}$}

Foram analisados os ácidos lático, glicólico, pirúvico, succínico, cáprico, citramálico, láurico, mirístico e palmítico. A metodologia envolveu a evaporação à secura de $20,0 \mathrm{~mL}$ de cachaça em temperatura ambiente sob fluxo de nitrogênio e subsequente adição de $200 \mu \mathrm{L}$ da solução derivatizante $(100 \mu \mathrm{L}$ de $\mathrm{N}$-methyl$\mathrm{N}$-trimethylsilyltrifluoroacetamide - MSTFA) e $100 \mu \mathrm{L}$ de acido nonanoico - padrão interno, $100 \mathrm{mg} \mathrm{L}^{-1} \mathrm{em}$ uma solução de acetonitrila). Foi utilizado para a análise, um cromatógrafo para fase gasosa, modelo Hewlett-Packard 5890, equipado com detector de ionização por chama (FID - Flame Ionization Detector). Uma coluna capilar DB-5 (5\%-phenyl-methylpolysiloxane; $50 \mathrm{~m}$ x 0,20 mm x 0,33 $\mu \mathrm{m}$ ) foi utilizada para a separação dos respectivos derivados silânicos dos ácidos orgânicos. A programação da temperatura do forno foi de $60{ }^{\circ} \mathrm{C}(2 \mathrm{~min})$ até $100{ }^{\circ} \mathrm{C}$ em uma razão de $25^{\circ} \mathrm{C} \mathrm{min}{ }^{-1}$; de 100 até $300{ }^{\circ} \mathrm{C}(5 \mathrm{~min})$ à razão de $10{ }^{\circ} \mathrm{C} \mathrm{min}^{-1}$. $\mathrm{O}$ volume injetado de amostra foi de $1 \mu \mathrm{L}$, utilizando o modo split (1:15). A identificação e a quantificação dos compostos foram realizadas por comparação do tempo de retenção com os respectivos padrões analíticos e pela curva de calibração, respectivamente.

\section{Análise multivariada}

A análise de componentes principais (PCA - Principal Components Analysis) foi utilizada com o objetivo de reduzir a dimensão do conjunto de dados, através da combinação linear das variáveis independentes originais. ${ }^{17}$

A análise hierárquica de grupos (HCA - Hierarchical Cluster Analysis) foi também utilizada no intuito de se observar o grau de similaridade entre os destilados. Esta metodologia calcula e compara as distâncias nos gráficos (dendrogramas) de HCA entre as amostras. Quanto menores estas distâncias, mais similares entre si serão as amostras. Seu principal objetivo é observar agrupamentos naturais entre as amostras, de acordo com as semelhanças entre as variáveis estudadas.

A matriz de dados utilizada em ambas as análises foi constituída pelos resultados analíticos das frações dos destilados em alambiques e colunas. A mesma foi estruturada utilizando todo o conjunto de dados (Tabela 1S, material suplementar) contendo 24 linhas (número de amostras dos destilados de cachaça) e 39 colunas correspondentes às concentrações dos compostos químicos analisados (variáveis). O pré-processamento foi realizado pelo autoescalonamento dos dados.

As técnicas de PCA e de HCA foram aplicadas utilizando o programa Minitab 15.1.1 $\left(\right.$ MINITAB $^{\circledR}$ e MINITAB $\log _{0^{\text {TM }}}$ da Minitab Inc.). 


\section{RESULTADOS E DISCUSSÃO}

A Figura 1 apresenta o perfil quantitativo (em valores medianos) para os compostos químicos analisados nas três frações do destilado de alambique (cabeça, coração e cauda) e do destilado de coluna. São similares os perfis de alcoóis e ésteres totais para os destilados de coluna e a "fração coração" do alambique. Quando comparadas as concentrações de alcoóis e ésteres totais das frações "cabeça" e "coração", se observa que o primeiro corte reduziu essas concentrações no "coração" à aproximadamente metade e a um décimo, respectivamente, dos valores correspondentes destes compostos na fração "cabeça". Comportamento semelhante foi observado com relação à concentração dos aldeídos, a qual apresenta uma variação significativa entre as três frações do alambique, devido à aplicação dos cortes. Quando comparamos as concentrações de aldeídos totais entre a fração "coração" e o destilado de coluna, este último apresentou concentrações três vezes superiores às do produto de alambique.

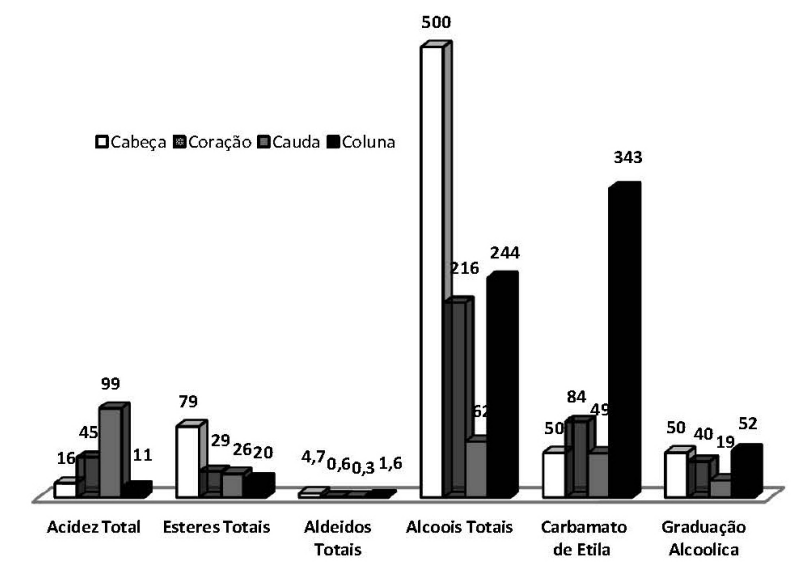

Figura 1. Perfil quantitativo dos destilados de alambique e de colunas, obtidos a partir de um mesmo vinho

Quanto à acidez total, as cachaças de coluna apresentaram concentrações inferiores às das três frações do alambique. O segundo corte realizado entre as frações de "coração" e "cauda" reduziu à metade a acidez total da fração "coração".

Foi sugerido anteriormente, ${ }^{14,18-20}$ que as cachaças destiladas em colunas de aço inox, em geral, apresentam concentrações de carbamato de etila superiores às das cachaças de alambique. A Tabela 1 apresenta teores de carbamato de etila para as três frações de alambique e do correspondente destilado de coluna, considerando-se em cada linha, o mesmo vinho. Estes resultados experimentais indicam que a concentração de carbamato de etila nas três frações do alambique decresce na seguinte ordem: "cabeça" > "coração" > "cauda".

Tabela 1. Concentração de carbamato de etila $\left(\mu \mathrm{L} \mathrm{L}^{-1}\right)$ nas três frações de destilado de alambique e do destilado de coluna, obtidos a partir de um mesmo vinho

\begin{tabular}{ccccc}
\hline Vinho & Cabeça & Coração & Cauda & Coluna \\
\hline Vinho 29 & 247 & 152 & 75 & 147 \\
Vinho 30 & $<\mathrm{L} \mathrm{Q}$ & $<\mathrm{L} \mathrm{Q}$ & $<\mathrm{L} \mathrm{Q}$ & $<\mathrm{L} \mathrm{Q}$ \\
Vinho 31 & 66 & 58 & $<\mathrm{L} \mathrm{Q}$ & 125 \\
Vinho 32 & 101 & $<\mathrm{L} \mathrm{Q}$ & 79 & $<\mathrm{L} \mathrm{Q}$ \\
Vinho 33 & 583 & 216 & 63 & 812 \\
Vinho 34 & 395 & 152 & 99 & 644 \\
\hline
\end{tabular}

$<$ L. Q = Abaixo do Limite Quantificação (40 ppb); Incerteza $\pm 5 \%$
As somas das concentrações de carbamato das frações "cabeça", "coração" e "cauda" dos destilados de alambique são, em geral, compatíveis com o teor deste, no destilado de coluna. Assim, as cachaças oriundas dos alambiques tendem a apresentar menores concentrações de carbamato com relação ao produto de colunas, devido ao processo de cortes.

Galinaro et al. ${ }^{20}$ demonstraram que durante a primeira semana após a destilação, ocorre um aumento gradual na concentração de carbamato de etila em aguardentes oriundas do mesmo vinho e destiladas em alambique e em coluna. Após este período, ocorre uma estabilização no teor de uretana. Desta forma, o carbamato de etila formado pós-destilação deve-se à presença de potenciais precursores nas diversas frações do destilado. ${ }^{20,21}$ Entretanto, as diferenças entre as concentrações de uretana nos destilados de coluna e nas frações de alambique, recém-obtidas, são devidas ao processo de destilação per se. Isto ocorre independentemente do processo fermentativo.

Foi aplicada análise multivariada ao conjunto de dados analíticos (Tabela 1S, material suplementar) a fim de verificar as possíveis semelhanças entre as amostras. A análise de componentes principais indica no gráfico de scores (Figura $1 \mathrm{~S}$, material suplementar) a formação de quatro agrupamentos distintos, correspondentes a cada uma das três frações de alambique e ao destilado de coluna. A PCA foi capaz de discriminar os quatros diferentes tipos de destilado com uma variância total de 71,2 \% explicada através da soma das três primeiras componentes principais (PC1, PC2 e PC3).

O gráfico de loading (Figura $1 \mathrm{~S}$, material suplementar) evidencia quais os compostos mais relevantes para a distribuição das amostras no espaço. Os compostos responsáveis pela definição e consequente separação do grupo referente à fração de "cabeça" foram os alcoóis superiores, ésteres (exceto o lactato de etila), aldeídos (exceto o 5-HMF), mais voláteis que o etanol e os ácidos graxos de cadeia longa (cáprico, láurico, mirístico e palmítico) menos voláteis que o etanol e mais solúveis em etanol do que em água. ${ }^{5,6}$ Os ácidos acético, lático, citramálico, glicólico, succínico e pirúvico, lactato de etila e 5-HMF foram as variáveis mais representativas para a formação do grupo correspondente às amostras da fração de cauda do destilado de alambique. Tais comportamentos são semelhantes ao descrito no trabalho de Leauté, ${ }^{6}$ o qual retrata a distribuição dos compostos químicos durante o processo de destilação do conhaque.

Um refinamento desta análise multivariada foi efetuado considerando-se os pesos de cada variável nas correspondentes componentes principais (PC1, PC2 e PC3) da Figura 1S do material suplementar. Foram selecionadas 11 variáveis das 39 originais: lactato de etila, acetato de etila, álcool isoamílico, carbamato de etila, acetaldeído, ácidos cáprico, láurico, lático e acético, benzaldeído e 5-HMF. Estas permitiram a discriminação clara dos quatro grupos formados no gráfico de scores (Figura 2). Este número reduzido de variáveis, simplificando o procedimento, não implicou em perda de qualidade do resultado da análise, pelo contrário, um aumento na variância de $10,5 \%$ foi observado $(\mathrm{PC} 1=49,5 \%, \mathrm{PC} 2=17,8 \%$ e $\mathrm{PC} 3=14,5 \%)$ com relação ao resultado anterior. De acordo com o gráfico de loading (Figura 2), acetato de etila, álcool isoamílico, acetaldeído e os ácidos cáprico e láurico contribuíram para a separação dos grupos na PC1 (49,5\%), caracterizando o grupo referente à fração "cabeça". O lactato de etila, 5-HMF e os ácidos lático e acético contribuíram para a separação na mesma $\mathrm{PC} 1$, caracterizando o grupo referente à fração "cauda". Carbamato de etila e benzaldeído contribuem com a separação no eixo da PC2 $(17,8 \%)$ e caracterizam o grupo referente às cachaças de coluna.

Aplicando análise de componentes principais ao conjunto de descritores propostos anteriormente, ${ }^{9}$ acrescida dos resultados para lactato de etila e para os ácidos cáprico, láurico, mirístico, palmítico e lático, importantes na distinção entre destilados de alambique e 

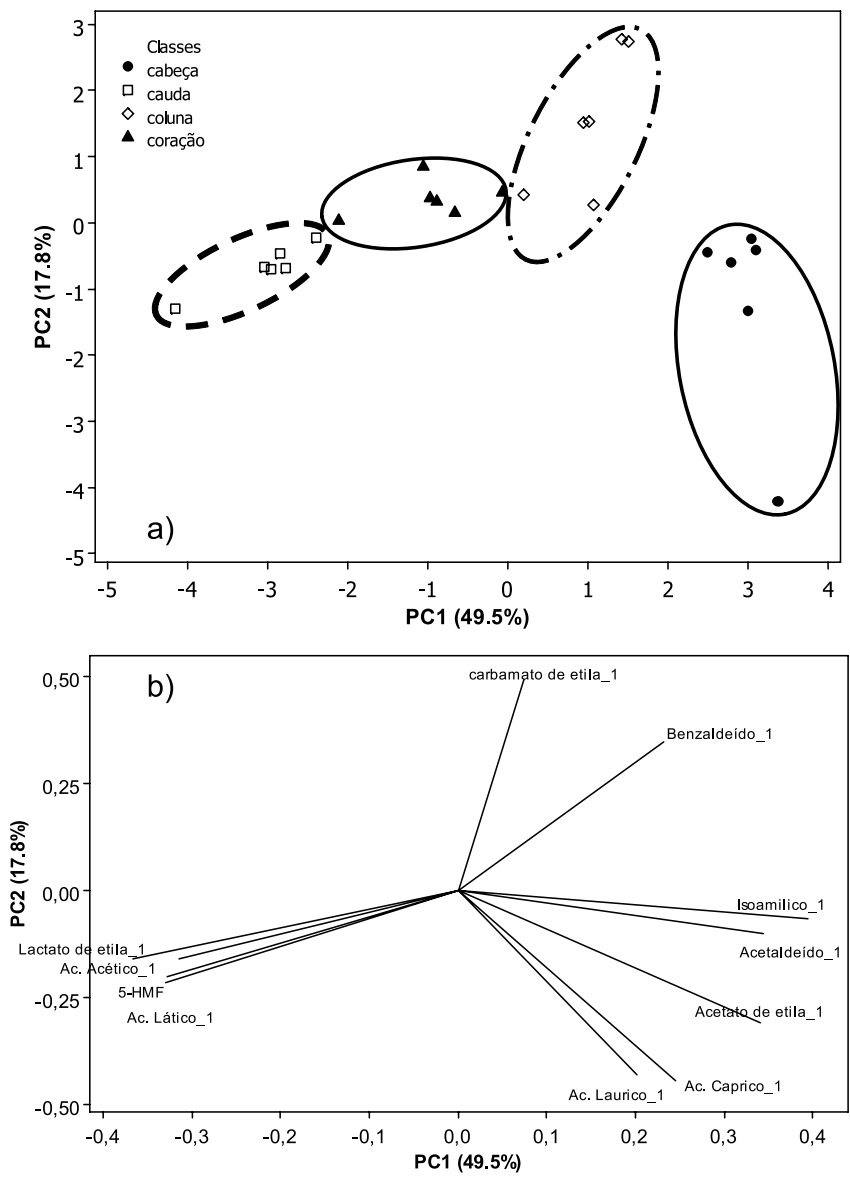

Figura 2. Análise de componentes principais de amostras de vinhos destilados em alambiques e em colunas: a) gráfico de scores e b) gráfico de loading

coluna, foi observado um aumento de $34,4 \%$ na capacidade discriminante entre ambos os destilados $(\mathrm{PC} 1=62,1 \%$; $\mathrm{PC} 2=23,3 \%$; $\mathrm{PC} 3=$ $9,3 \%$ - Figura $2 \mathrm{~S}$, material suplementar).

O dendrograma da Figura 3 foi construído utilizando-se todas as 39 variáveis do banco de dados. O método de ligação Ward's, utilizado para determinar a distância entre os grupos das amostras, e a distância de Manhattan, utilizada para medir a distância entre as amostras, foram os algoritmos hierárquicos estatísticos que melhor agruparam as amostras, de acordo com as propriedades dos dados analíticos. Os destilados de alambique e de coluna estão claramente diferenciados na Figura 3, reforçando as conclusões da análise por PCA. De acordo com os resultados, o grupo correspondente à fração

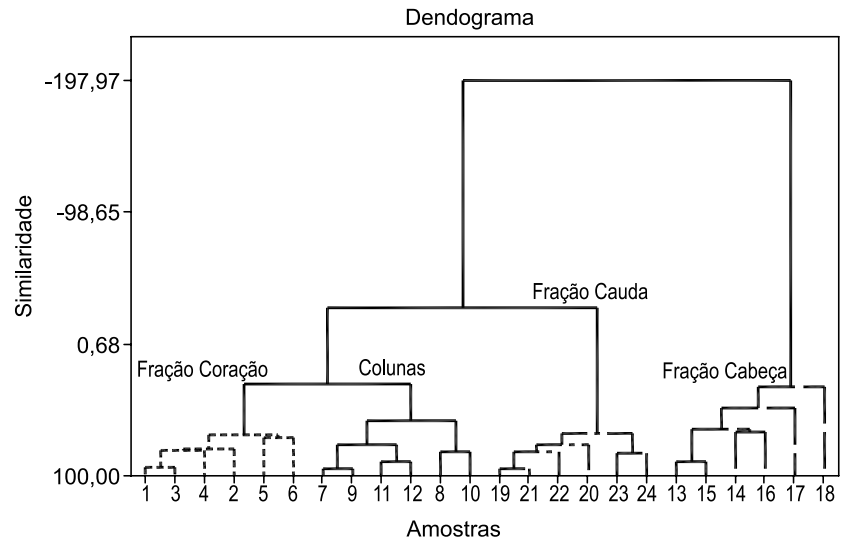

Figura 3. Análise hierárquica de grupos de amostras de vinhos destilados em alambiques e em colunas "cabeça" apresentou a menor similaridade com relação aos demais grupos, seguidos da fração "cauda".

A avaliação dos resultados analíticos pelas técnicas quimiométricas aqui utilizadas sugere que, embora não ocorrendo o processo de cortes durante a destilação em colunas, a composição química destes destilados, devido ao elevado número de bandejas de destilação (pratos teóricos), apresenta teores reduzidos dos compostos encontrados nas frações de cauda e cabeça.

\section{CONCLUSÃO}

Amostras do mesmo vinho foram destiladas em alambiques e colunas. O tratamento quimiométrico dos resultados analíticos para 39 compostos orgânicos confirmou que as frações "cabeça", "coração" e "cauda" são quimicamente distintas entre si e o correspondente destilado do mesmo vinho destilado em coluna. Justifica-se, portanto, com base nestes resultados e em trabalhos anteriores, a inclusão no rótulo do destilado da informação quanto ao processo de destilação.

No processo em alambiques o carbamato de etila concentra-se preferencialmente na fração "cabeça". Embora dotado de apenas um prato teórico, devido aos cortes, o produto de alambique ("coração") apresenta teor de carbamato de etila inferior ao do destilado do mesmo vinho produzido em coluna

\section{MATERIAL SUPLEMENTAR}

O material suplementar, disponível em http://quimicanovasbq. org.br, na forma de arquivo PDF, com acesso livre, é composto pelas Figuras 1S, 2S e a Tabela 1S. A Figura 1S apresenta a análise de componentes principais contendo todas as variáveis. A Figura $2 \mathrm{~S}$ mostra a inclusão de novos descritores na análise de componentes principais gerada por Reche et al. ${ }^{9}$ na qual se observa uma melhora significativa na capacidade discriminante entre as amostras destiladas em alambique e em coluna. A Tabela $1 \mathrm{~S}$ apresenta os valores de concentração para os 38 compostos orgânicos analisados em cada uma das amostras das frações de alambique e do destilado de coluna obtidos de um mesmo vinho.

\section{AGRADECIMENTOS}

Ao CNPq, à CAPES e FAPESP pelo apoio financeiro.

\section{REFERÊNCIAS}

1. Lima, U. A.; Aguardente: fabricação em pequenas destilarias, $1^{\mathrm{a}}$ ed., FEALQ: Piracicaba, 1999.

2. Novaes, F. V.; Noções básicas sobre a teoria da destilação, ESALQ: Piracicaba, 1994, publicação interna.

3. Maia, A. B. R. A.; Campelo, E. A. P.; Tecnologia da Cachaça de Alambique, SEBRAE/MG, SINDBEBIDAS: Belo Horizonte, 2006.

4. Mutton, M. J. R.; Mutton, M. A. Em Tecnologia de bebidas; Venturini, W. G. F., ed.; $1^{\text {a }}$ ed., Edgard Blucher: São Paulo, 2005.

5. Weast, R. C.; Handbook of Chemistry and Physics, $58^{\text {th }}$ ed., CRC Press: Florida, 1978.

6. Léauté, R.; Am. J. Enol. Vitic. 1990, 41, 90.

7. Maia, A. B. R. A.: Campelo, E. A. P.; Tecnologia da Cachaça de Alambique, SEBRAE/MG, SINDBEBIDAS: Belo Horizonte, 2006.

8. Verdi, A. R.; Informações Econômicas - SP 2006, 36, 93.

9. Reche, R. V.; Leite-Neto, A. F.; Silva, A. A.; Galinaro, C. A.; De Osti, R. Z.; Franco, D. W.; J. Agric. Food Chem. 2007, 55, 6603.

10. De Souza, P. P.; De Oliveira, L. C. A.; Catharino, R. R.; Eberlin, M. N.; Augusti, D. V.; Siebald, H. G. L.; Augusti, R.; Food Chem. 2009, 115, 1064. 
11. Penteado, J. C. P.; Masini, J. C.; Anal. Lett. 2009, 42, 2747.

12. Boscolo, M.; Bezerra, C. W B.; Cardoso, D. R.; Lima Neto, B. S.; Franco, D. W.; J. Braz. Chem. Soc. 2000, 11, 86.

13. Cardoso, D. R.; Bettin, S. M.; Reche, R. V.; Lima Neto, B. S.; Franco, D. W.; J. Food Comp. Anal. 2003, 16, 563.

14. Andrade-Sobrinho, L. G.; Boscolo, M.; Lima-Neto, B. S.; Franco, D. W.; Quim. Nova 2002, 25, 1074.

15. Nascimento, E. S. P.; Cardoso, D. R.; Franco, D. W.; J. Agric. Food Chem. 2008, 56, 5488.

16. Serafim, F. A. T.; Buchviser, S. F.; Galinaro, C. A.; Novaes, F. V.; Franco D. W.; Quim. Nova 2011, 34, 28.
17. Beebe, K. R.: Pell, R. J.: Seasholtz, M. B.; Chemometrics: A Practical Guide, $1^{\text {st }}$ ed., John Wiley Sons: New York, 1998.

18. Bruno, S. N. F.; Vaitsman, D. S.; Kunigami, C. N.; Brasil, M. G.; Food Chem. 2007, 104, 1345.

19. Nóbrega, I. C. C.; Pereira, J. A. P.; Paiva, J. E.; Lachenmeier, D. W.; Food Chem. 2011, 127, 1243.

20. Galinaro, C. A.; Franco, D. W.; Quim. Nova 2011, 34, 996.

21. Nóbrega, I. C. C.; Pereira, J. A. P.; Paiva, J. E.; Lachenmeier, D. W.; Food Chem. 2009, 117, 693. 
COMPARAÇÃO DO PERFIL QUÍMICO ENTRE CACHAÇAS DE UM MESMO VINHO DESTILADAS EM ALAMBIQUES E EM COLUNAS

Felipe Augusto Thobias Serafim, Alexandre Ataíde da Silva, Carlos Alexandre Galinaro e Douglas Wagner Franco* Instituto de Química de São Carlos, Universidade de São Paulo, CP 780, 13560-970 São Carlos - SP, Brasil
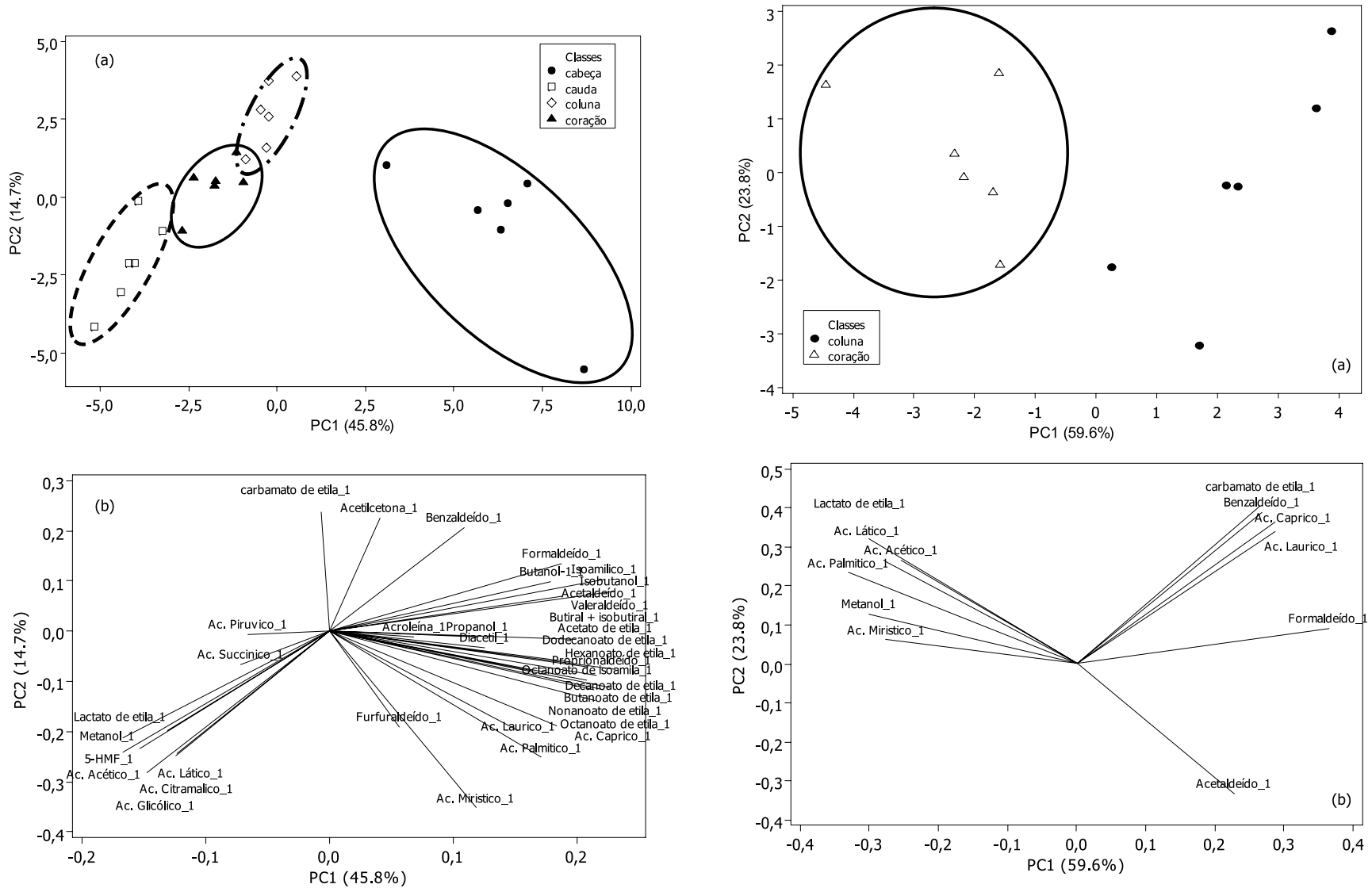

Figura 1S. Análise de componentes principais de amostras de vinhos destilados em alambiques e em colunas: a) gráfico de scores e b) gráfico de loading

Figura 2S. Análise de componentes principais das cachaças de alambiques e de colunas: a) gráfico de scores e b) gráfico de loading 


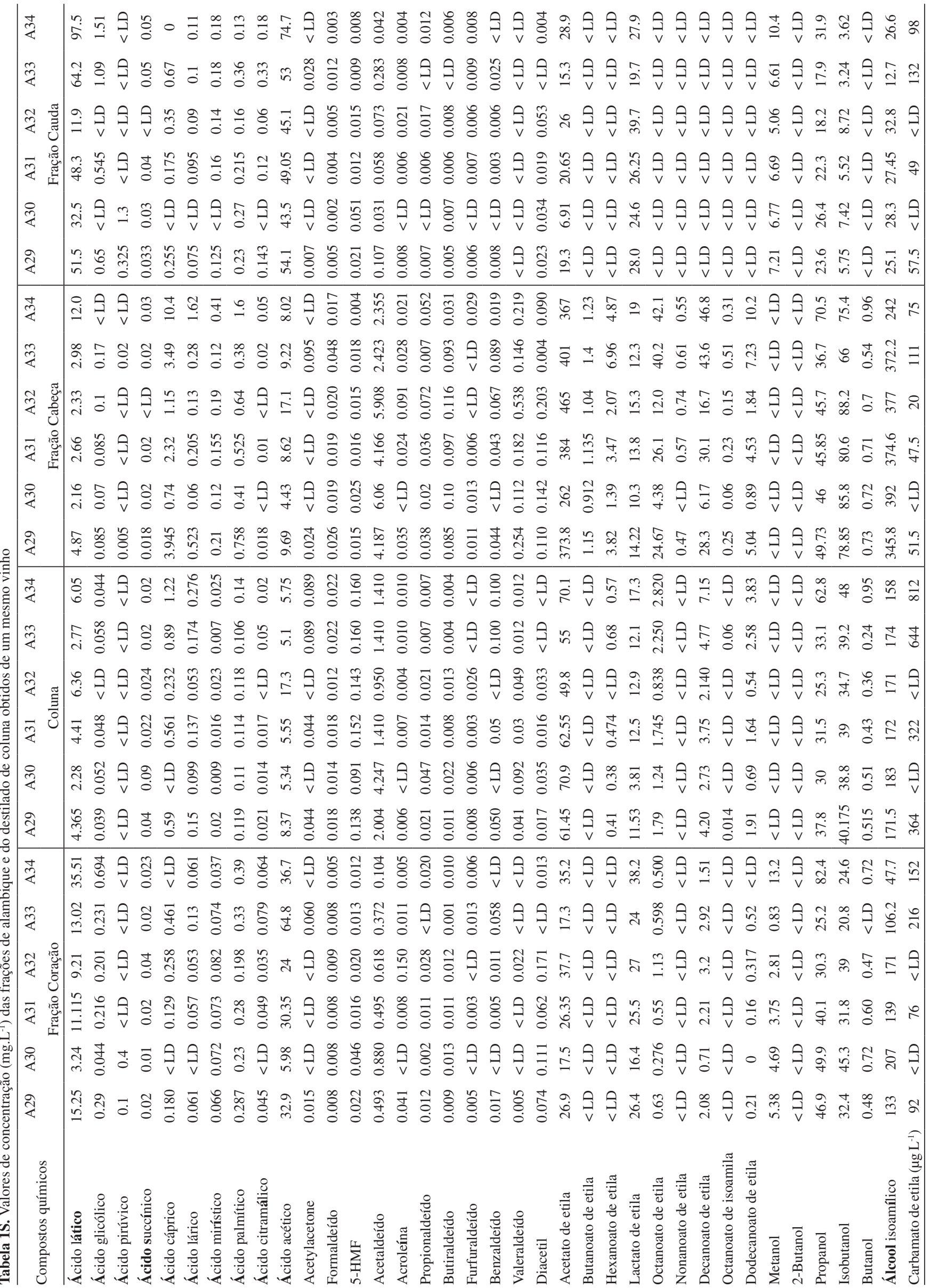

